\title{
Tahap Kemahiran Hidup Masyarakat Miskin di Sabah dari Perspektif Psikososial
}

\author{
Othman Che Jusoh ${ }^{1}$, Hamidi Ismail ${ }^{* 2}$ \\ ${ }^{1}$ Kolej Undang-undang, Kerajaan dan Pengajian Antarabangsa \\ Universiti Utara Malaysia, Kedah, MALAYSIA \\ ${ }^{2}$ Kolej Undang-undang, Kerajaan dan Pengajian Antarabangsa \\ Universiti Utara Malaysia, Kedah, MALAYSIA \\ * Corresponding Author : hamidi@uum.edu.my \\ DOI: https://doi.org/10.30880/jts.2018.10.01.005
}

\begin{abstract}
The level of life skills of the poor in handling poverty in Sabah is still unclear. The objective of this article is to determine the level of life skills of the poor in Sabah based on the constructs proposed by Life Skills Theory by the World Health Organization in 1998. Measuring constructs for this study are aspects of problem solving, decision making, self-esteem, creative thinking, self-awareness, critical thinking, empathy, effective communication, self-esteem and mental stability. A total of 1,210 heads of households were involved in surveys throughout the State of Sabah. The findings of the study were three of the 10 living skills constructs at high level and the rest were in the medium category. This study is important in the context of assessing the level of life skills of the poor in Sabah from a psychosocial perspective.
\end{abstract}

Keywords : Life Skills; Life Skills Theory; Poor People; Psychosocial; Sabah

\section{Pendahuluan}

Kemahiran hidup berdasarkan Teori Kemahiran Hidup oleh Pertubuhan Kesihatan Sedunia (WHO) pada tahun 1998 bermaksud kemampuan diri yang boleh membantu seseorang melakukan usaha atau kerja secara berkesan. Kemahiran hidup diperlukan untuk menjalankan usaha dengan sabar sehingga berjaya melengkapkan segala ikhtiar. Seseorang yang berkemahiran baik boleh menjalankan tugas dengan hanya menggunakan sedikit masa, kurang tenaga tetapi menghasilkan keputusan yang berkualiti (WHO, 1999). Ia merupakan asas penting bagi sesebuah isirumah miskin agar mereka dapat keluar daripada kancah kemiskinan. Dalam konteks Malaysia, ukuran kemiskinan yang biasa diguna pakai oleh kerajaan adalah secara mutlak dan ukuran biasa digunakan adalah melalui pendapatan median isirumah atau Pendapatan Garis Kemiskinan atau PGK (Unit Perancang Ekonomi, 2017). Negeri Sabah merupakan satu daripada negeri yang berada dalam Persekutuan Malaysia dan merupakan negeri kedua terbesar di Malaysia selepas Negeri Sarawak. Sabah merupakan sebuah negeri yang paling miskin di Malaysia sehingga tahun 2016 (Unit Perancang Ekonomi, 2017) dan perlu mendapat tempat sebagai agenda kajian ilmiah. Laporan kemiskinan yang dikeluarkan oleh Unit Perancang Ekonomi (2017) menggambarkan insiden miskin di Sabah adalah seramai 11,400 keluarga. Golongan yang dikatakan miskin bagi negeri Sabah adalah mereka berpendapatan PGK RM 1,170.00 sebulan.

Kajian terdahulu berkaitan kemiskinan lebih menumpukan kepada beberapa perkara asas iaitu tentang ukuran kemiskinan sepertimana kajian oleh Alkire dan Seth (2009), Asselin dan Anh (2010), Brandolini (2001), Haveman dan Bershadker (2001), Mussard dan Alperin (2008), Naveed dan Tanweer-ul-Islam (2010) serta Sen (1987; 1999). Dalam konteks kajian faktor kemiskinan pula telah dikaji oleh Abbott dan Pollard (2004), Li dan Schwaub (2004) serta Wade (2001). Seterusnya, aspek membahagikan status kemiskinan atau bentuk kemiskinan pula dijalankan oleh Notten (2008) dan Wagle (2004), manakala pendekatan dalam menganalisis kemiskinan pula dijalankan oleh Deutsch dan Silber (2005). Penelitian terhadap kajian lepas dari perspektif psikologi sosial atau psikososial mendapati terdapat ruang atau lompang keilmuan (research gap) yang gagal diteliti secara khusus, terutamanya aspek tahap kemahiran 
hidup masyarakat miskin menangani kemiskinan keluarga, terutamanya di Sabah. Hal ini menjadi sumbangan kepada keilmuan kajian atau turut menyumbang kepada lompang keilmuan (Rajah 1).

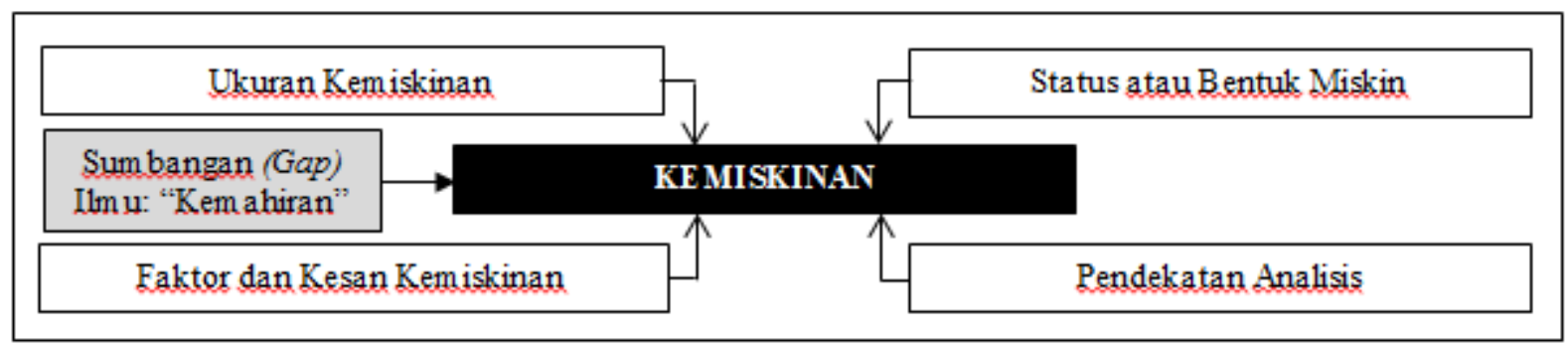

Rajah 1 : Rumusan kajian terdahulu dan sumbangan ilmu

Sekaligus, ia juga menjelaskan wujudnya masalah kajian dalam konteks keilmuan iaitu "tahap kemahiran hidup masyarakat miskin menangani kemiskinan keluarga di Sabah yang kurang jelas”. Justeru, objektif artikel ini adalah untuk menentukan tahap kemahiran hidup masyarakat miskin di Sabah berdasarkan Teori Kemahiran Hidup oleh WHO (1999).

\section{Teori Kemahiran Hidup}

Menurut WHO (1999), kemahiran merupakan kemampuan diri yang boleh membantu melakukan usaha atau kerja secara berkesan. Kemahiran diperlukan untuk menjalankan usaha dengan sabar sehingga berjaya melengkapkan segala ikhtiar. Seseorang yang berkemahiran baik boleh menjalankan tugas dengan hanya menggunakan sedikit masa, kurang tenaga tetapi menghasilkan keputusan yang berkualiti. Ia boleh diperoleh sama ada melalui pembelajaran formal di sekolah, pengalaman kerja, hobi yang kekal, pembacaan, teguran rakan sebidang atau sebagainya. WHO (1999) turut membincangkan bahawa kemahiran mempunyai jenis-jenisnya yang berbeza mengikut persekitaran hidup atau pekerjaan. Pada umumnya, kemahiran boleh dibahagikan kepada beberapa jenis iaitu: pertama, membaca; kedua, berbahasa; ketiga, mencari rezeki; keempat, vokasional dan teknikal; kelima, pekerjaan; keenam, berbudaya; ketujuh, bersukan dan berrekreasi; dan kelapan adalah kemahiran hidup atau diri seseorang. Kemahiran hidup atau diri seseorang merupakan satu daripada lapan senarai jenis kemahiran yang dibincangkan oleh Teori Kemahiran Hidup (Life Skills Theory) 1998 oleh WHO (1999). Penerimaan terhadap kemahiran diri secara keseluruhannya akan menjadikan hubungan antara anggota masyarakat atau keluarga lebih baik sehingga boleh membawa kepada perspektif kehidupan lebih positif dan sihat.

Menurut WHO (1999), kemahiran hidup sememangnya hadir dalam diri setiap individu. Bagi memastikan kemahiran diri lebih menyerlah, ia perlu digilap sepanjang masa, bukan hanya dipraktikkan sekali seumur hidup atau jarang-jarang dilakukan. Setiap diri manusia perlu memiliki kemahiran diri bagi memastikan mereka boleh hidup dengan baik walau menghadapi pelbagai masalah dalam kehidupan. Oleh sebab itu, Herbst et al. (2008) dan Rosario et al. (2002) berpendapat kajian kemahiran diri ini bukan perkara baharu dalam bidang kesihatan manusia oleh WHO kerana ia turut sesuai digunakan oleh pengkaji bidang pendidikan, pencegahan jenayah, penyelesaian konflik, masalah kehidupan masyarakat, media, penderaan manusia, isu alam sekitar, pembangunan kerjaya dan pekerjaan serta perkahwinan. Walau bagaimanapun, selain daripada bidang kajian di atas, ia turut boleh diaplikasi kepada kajian sosial secara menyeluruh disebabkan oleh teori ini bersifat psikologi sosial.

Kemahiran diri yang dimaksudkan oleh teori ini adalah kebolehan menjalankan tingkah laku positif berdasarkan situasi berubah-ubah setiap individu semasa berhadapan dengan cabaran hidup setiap hari. Kajian menangani kemiskinan keluarga di Sabah yang cuba dikaitkan dengan aspek kemahiran diri isirumah adalah menggunakan Teori Kemahiran Hidup yang dibangunkan dan digunakan oleh WHO pada tahun 1998. Menurut Berger et al. (2001) dan Hodge et al. (2012), pendekatannya lebih berasaskan kemahiran diri atau hidup manusia bagi menyelesaikan masalah yang dihadapi mereka dari perspektif psikososial. DuBrin (2016) dan Wilson et al. (2010) berpendapat WHO membangunkan teori ini dalam konteks kesihatan diri manusia dari aspek psikologi sosial kerana pesakit kerap berhadapan dengan gangguan norma positif dalam diri. Sebanyak 10 norma (konstruk) yang menjadi ukuran kepada teori ini dan perlu berkeadaan baik hubungannya antara setiap norma hidup untuk mendapatkan keputusan analisis yang baik tentang diri dalam menghadapi masalah kemiskinan. Norma-norma hidup positif penting yang membentuk konstruk ukuran kajian merangkumi aspek penyelesaian masalah, pembuatan keputusan, ketahanan diri, pemikiran kreatif, kesedaran diri, pemikiran kritis, empati, komunikasi berkesan, keyakinan diri dan kestabilan pemikiran.

\section{Metodologi}

Sabah terletak di utara Pulau Borneo iaitu pulau ketiga terbesar di dunia dan ibu negeri bagi Sabah adalah Kota Kinabalu yang dahulunya terkenal dengan nama Jesselton. Negeri Sabah mempunyai lima Bahagian (Division) iaitu 
Kudat, Pantai Barat, Pedalaman, Sandakan dan Tawau; seterusnya dibahagikan kepada 25 daerah iaitu Kudat, Pitas, Kota Marudu, Kota Belud, Tuaran, Kota Kinabalu, Ranau, Beluran, Putatan, Penampang, Kuala Penyu, Papar, Tambunan, Beaufort, Keningau, Tenom, Sipitang, Nabawan, Tongod, Sandakan, Kinabatangan, Lahad Datu, Kunak, Tawau dan Semporna (Jabatan Perancang Bandar dan Desa Negeri Sabah, 2011).

Pengiraan saiz sampel dilakukan berdasarkan kepada cadangan Krejcie dan Morgan (1970) yang menetapkan seramai 1,210 responden dengan mengambil kira darjah keyakinan setinggi 99 peratus dan darjah ketepatan sampel setinggi 0.035 (atau ralat sampel 3.5 peratus). Langkah seterusnya adalah menetapkan: siapakah responden yang akan terlibat dengan kajian? Pengkaji mengenal pasti bakal responden yang berpendapatan RM1,170.00 ke bawah tetapi tidak kurang daripada RM710.00. Ini kerana, jumlah pendapatan RM710.00 dan ke bawah adalah dalam kategori miskin tegar. Responden diambil melalui teknik bertujuan (purposive) dengan mensasarkan ketua isirumah miskin. Sungguhpun teknik ini kurang baik kerana tidak rawak, tetapi ia adalah sesuai memandangkan sukar mengenal pasti lokasi atau mereka yang benar-benar berada dalam kumpulan ini, ditambah pula dengan ketiadaan rekod yang sistematik atau lengkap. Kerja-kerja lapangan untuk menjawab kaji selidik yang dilakukan oleh pembanci seramai 50 orang adalah diselia oleh pengkaji dan dibantu oleh penyelia tesis. Borang kaji selidik dibahagikan kepada 10 bahagian bagi mewakili konstruk kajian iaitu bermula dengan latar belakang responden dan seterusnya tentang 10 aspek kemahiran hidup. Bentuk soalan kaji selidik Skala Likert 3 tahap, kecuali Bahagian A (latar belakang responden). Keseluruhan analisis adalah berbentuk deskriptif dengan menggunakan statistik min. Sekiranya nilai min dalam julat 1.00-1.67 (maka ia adalah tahap rendah), julat 1.68-2.33 (maka ia adalah tahap sederhana) dan julat 2.34-3.00 (maka ia adalah tahap tinggi). Mekanisma penilaian berdasarkan teori ini adalah perlu kesemua konstruk atau norma dalam keadaan semuanya positif bagi menentukan tahap kemahiran hidup yang baik.

\section{Hasil dan Perbincangan}

Dapatan kajian mempamirkan bahawa konstruk ukuran kemahiran hidup pada tahap tinggi adalah pembuatan keputusan bagi menangani kemiskinan (min 2.34), kesedaran diri menangani kemiskinan (min 2.51) dan empati dalam menangani kemiskinan (2.39). Hal ini boleh diterjemahkan bahawa masyarakat miskin di Sabah adalah baik dalam membuat keputusan, memiliki kesedaran dan berperasaan empati kepada keluarga dan pihak lain bagi menangani kemiskinan. Sementara lain-lain konstruk ukuran kemahiran hidup masih dalam keadaan sederhana iaitu antara julat 1.68-2.33 (Jadual 1). Walau bagaimanapun, konstruk ukuran paling tinggi tahap kemahiran hidup adalah kesedaran diri menangani kemiskinan (min 2.51), manakala paling rendah adalah keyakinan diri menangani kemiskinan (min 2.12) dan berkongsi kedudukan dengan konstruk kestabilan pemikiran menangani kemiskinan. Sungguhpun begitu, kajian mendapati bahawa kemahiran hidup masyarakat miskin di Sabah dari perspektif psikososial adalah pada tahap sederhana dengan nilai min keseluruhan mencatat bacaan 2.30 .

Jadual 1. Tahap kemahiran hidup masyarakat miskin di Sabah

\begin{tabular}{cccc}
\hline No & Konstruk ukuran kemahiran hidup & Min & Tahap \\
\hline 1. & Penyelesaian masalah kemiskinan & 2.32 & Sederhana \\
2. & Pembuatan keputusan bagi menangani kemiskinan & 2.34 & Tinggi \\
3. & Ketahanan diri menangani kemiskinan & 2.32 & Sederhana \\
4. & Pemikiran kreatif menangani kemiskinan & 2.31 & Sederhana \\
5. & Kesedaran diri menangani kemiskinan & 2.51 & Tinggi \\
6. & Pemikiran kritis menangani kemiskinan & 2.24 & Sederhana \\
7. & Empati dalam menangani kemiskinan & 2.39 & Tinggi \\
8. & Komunikasi berkesan menangani kemiskinan & 2.30 & Sederhana \\
9. & Keyakinan diri menangani kemiskinan & 2.12 & Sederhana \\
10 & Kestabilan pemikiran menangani kemiskinan & 2.12 & Sederhana \\
& Min atau tahap keseluruhan & $\mathbf{2 . 3 0}$ & Sederhana \\
\hline
\end{tabular}

$\mathrm{N}=1,210$

\section{Kesimpulan}

Secara keseluruhannya, permasalahan tentang tahap kemahiran hidup masyarakat miskin di Sabah yang kurang jelas melalui kajian terdahulu terjawab iaitu berada pada tahap sederhana. Memandangkan tahapnya masih sederhana, maka langkah strategik perlu dijalankan oleh pihak yang terlibat dengan pembasmian kemiskinan, selain aspek psikososial responden miskin itu sendiri. Namun begitu, perkara penting yang perlu ditingkatkan adalah aspek keperluan kepada perkara berkaitan penyelesaian masalah, ketahanan diri, pemikiran kreatif, pemikiran kritis, komunikasi berkesan, keyakinan diri dan kestabilan pemikiran kerana masih berada pada tahap sederhana. 


\section{Rujukan}

Abbott, D. \& Pollard, S. (2004). Strengthening poverty analysis and strategies in the pacific. Pacific Department Hardship and Poverty in the Pacific, Asian Development Bank.

Alkire, S. \& Seth, S. (2009). Measuring multidimensional poverty in India: a new proposal. OPHI Working Paper No. 15. OPHI Working Paper No. 43. Oxford: University of Oxford Press.

Asselin, L.M. \& Anh, V.T. (2010). Multidimensial poverty monitoring: a methodology and implementation in Vietnam. Vietnam's Socio-Economic Development Review 38.

Berger, B.E., Ferrans, C.E. \& Lashley, F.R. (2001). Measuring stigma in people with HIV: psychometric assessment of the HIV Stigma Scale. Res Nurs Heal. 24, 518-529.

Brandolini, A. (2001). Patterns of economic inequality in western democracies: some facts on levels and trends. PSOnline www.apsanet.org/ [diakses pada 12 Mac 2017].

Deutsch, J. \& Silber, J. (2005). Measuring multidimensional poverty: an empirical comparison of various approaches. The Review of Income and Wealth 51, 145-174.

DuBrin, A.J. (2016). Human relations for career and personal success: concepts, applications, and skills. New York: Pearson Education.

Haveman, R. \& Bershadker, A. (2001). The "Inability to be self-reliant" as an indicator of poverty: trends for the U.S., 1975-97. Social Sciences and Humanity 47, 335-360.

Herbst, J.H., Jacobs, E.D., Finlayson, T.J., McKleroy, V.S., Neumann, M.S. \& Crepaz, N. (2008). Estimating HIV prevalence and risk behaviors of transgender persons in the United States: a systematic review. AIDS Behav. 12(1), 117.

Hodge, K., Danish, S. \& Martin, J. (2012). Developing a conceptual framework for life skills interventions. The Counseling Psychologist XX(X), 1-28.

Jabatan Perancang Bandar dan Desa Negeri Sabah. (2011). Rancangan Struktur Negeri Sabah 2020. Kota Kinabalu: JPBD Sabah.

Krejcie, R.V. \& Morgan, D.W. (1970). Determining sample size for research activities. Educational and Psychological Measurement 40, 53-76.

Li, Q. \& Schwaub, D. (2004). Economic globalization and transnational terrorism: a pooled time-series analysis. Journal of Conflict Resolution 48(2), 230-258.

Mussard, S. \& Alperin, M.N.P. (2008). Inequalities in multidimensional poverty: evidence from Argentina. Applied Economics Letters 15, 759-765.

Naveed, A. \& Tanweer-ul-Islam. (2010). Estimating multidimensional poverty and identifying the poor in Pakistan: an alternative approach. RECOUP Working Paper No. 28. Research Consortium on Educational Outcomes and Poverty.

Notten, G. (2008). Multidimensional poverty in the republic of Congo: being poor simultaneously in many ways. BWPI Working Paper 65. Brooks World Poverty Institute.

Rosario, M., Schrimshaw, E.W. \& Hunter, J. (2002). Gay-related stress and emotional distress among gay, lesbian, and bisexual youths: a longitudinal examination. J Consult Clin Psychol. 70(4), 967-975.

Sen, A. (1987). The standard of living. Cambridge: Cambridge University Press.

Sen, A. (1999). Development as freedom. Oxford: Oxford University Press.

Unit Perancang Ekonomi. (2017). Malaysia: measuring and monitoring poverty and inequality. Kuala Lumpur: United Nations Development Programme (UNDP), Malaysia. 
Wade, M.E. (2001). Women and salary negotiation: the costs of self-advocacy. Psychology of Women Quarterly 25, 65-76.

Wagle, U.R. (2004). Multidimensional poverty: an alternative measurement approach for the United States? Working Paper was presented at the 2007 Eastern Economics Association Conference in New York.

Wilson, E.C., Garofalo, R., Harris, D.R. \& Belzer, M. (2010). Sexual risk taking among transgender male-to-female youths with different partner types. Am J Public Health 100(8), 1500-1505.

World Health Organization (WHO). (1999). Partners in life skills education. http://www.who.int/en/ [diakses pada 15 Disember 2017]. 